\title{
Graft copolymerization of Acrylamide onto Bombax Costatum Calyx by initiator ceric ammonium nitrate: Study of effective grafting parameters for optimization
}

\author{
M.A. Hamma ${ }^{-A_{d a m a}}{ }^{1}$,S.A.Osemeahon ${ }^{2}$ and J.T. Barminas ${ }^{2}$ \\ ${ }^{I}$ Department of Chemistry, Federal College of Education PMB 2042, Yola Nigeria \\ ${ }^{2}$ Department of Chemistry, Modibbo Adama University of Technology, PMB 2076, Yola Nigeria
}

\begin{abstract}
The Graft copolymerization of Acrylamide monomer (AAm) onto Bombax Costatum Calyx (BCC) using ceric ammonium nitrate $(C A N)$ as initiator in aqueous medium to form grafted copolymer (BCC-g$P A A m)$ was investigated. The effect of different reaction conditions on the grafting has been studied by determining the grafting parameters, i.e. concentration of AAm, CAN, BCC, reaction time and temperature were carefully optimized to achieve the highest percent grafting yield $(\% G)$ and graft efficiency $(\% G E)$. Each of these parameters was varied one by one keeping other conditions constant in the reaction. The grafted and raw BCC were characterized by Fourier transform infrared spectroscopy to confirm the evidence of grafting. From the FTIR data it was ascertained that grafting has occurred considerably. Also from the results, it was observed that with increasing AAm, BCC, and CAN concentrations as well as reaction time and temperature the grafting parameters were increased, but further increase of reaction conditions disfavored these parameters. This was done to establish the optimum conditions of grafting. 1
\end{abstract}

Key words:Bombax costatum calyx, ceric ammonium nitrate, grafted copolymer, polyacrylamide, percent grafting yield and graft efficiency.

\section{Introduction}

Cellulose is the most abundant biomass material in nature, and possesses some promising properties, such as great mechanical strength, hydrophilicity, biocompatibility, biodegradability relative thermostabilization, high sorption capacity and alterable optical appearance (Nada et al., 2007; Kumar et al., 2011; Sadeghi et al., 2012). Thus, cellulose has been widely applied in many fields. It is frequently modified in the preparation of a wide range of new materials that have proved to be very useful in several and diverse fields of application (Khullar et al., 2008; Singha et al., 2011). The presence of three reactive hydroxyl groups on each glucan unit of cellulose makes it relatively easy to modify (Ouajai et al., 2004). One method of modifying cellulose that has been studied extensively is graft copolymerization (Ouajai et al., 2004; Jideonwa et al., 2006; Sadeghi et al., 2011).

Cellulose graft copolymers are very attractive because their products can readily be made to posses any number of the required properties (Mostafa et al., 2005; Soleimani et al., 2012). Great numbers of grafting methods have been developed, but the free radical methods of generating radicals on the cellulose backbone before grafting have received the greatest attention (Raju et al., 2007; Kauretal., 2010; Sadeghi et al., 2011). The use of ceric ions to generate free radicals which initiate grafting reactions has been one of the most reported (Ge et al., 2006; Taghizadeh et al., 2006; Osemeahon et al., 2008). Graft copolymerization can be carried out with different initiator systems. Among them, potassium persulfate, ammonium persulfate, benzoyl peroxide, azobisisobutyronitrile and ceric ammonium nitrate are widely used for the synthesis of graft copolymers (Onishi et al., 2004; Sadeghi et al., 2010; Sadeghi et al., 2011). Among various methods, graft copolymerization is most attractive because it is a useful technique for modifying the chemical and physical properties of natural polymers (Okieimen et al., 2003; Sadeghi et al., 2011).

The grafting process has two advantages. The first is to replace the hydroxyl group of C6 of the glucose units in the substrate by carboxyl group that attract the metal ions from the solution. The second is to decrease the number of the hydroxyl group in the polymer so that the hydrogen bonding between the polymer strands decreases, thus the crystalline index of the substrate decreases by introduction of this hydrophilic group so it becomes more chemically active (Zhang et al., 2007; Feng et al., 2010). Bombax costatum calyx (BCC) is a very good candidate bearing two types of reactive groups that can be grafted. Grafting of BCC allows the formation of functional derivatives by covalent binding of a molecule onto the BCC backbone.

Bombax Costatum is a fire resisting plant of Savannah and dry wood lands of Africa of family Bombacaseace. It is commonly called red flowered silk cotton tree in English, Joye in Fulfulde and Bamta in Bachama languages respectively. 
As a part of our ongoing research programme on chemical modification of Bombax costatum calyx, we were interested to study the graft copolymerization reactions with the intention of studying its swelling behavior and sorption capacity for the removal of heavy metal ions from aqueous solution. The present investigation describes the optimization of the reaction conditions of grafting of acrylamide monomer onto Bombax costatum calyx using ceric ammonium nitrates initiator.

\section{Materials}

\section{Materials And Methods}

Acrylamide, ceric ammonium nitrate, acetone and methanol were of BDH analytical grade and were used as supplied. Bombax Costatum calyx was collected from Dakri, Girei local Government Area, Adamawa State, Nigeria.

\section{Methods}

Preparation of Bombax Costatum Calyx Sample.

The Bombax Costatum calyx sample was sun dried, decoated and milled into powder. It was then sieved through a $100 \mu \mathrm{m}$ sieve screen to obtain fine powder and packaged in a polyethylene bag for further use.

\section{Synthesis of Graft Copolymer;}

The procedure for graft copolymerization of acrylamide (AAm) onto Bombax costatum calyx (BCC) was achieved by an adaptation of the methods described by (Hsu et al., 2002; Zohuriaan et al., 2005; Sadeghi et al., 2011). It wascarried out by weighing (0.5- $5 \mathrm{~g}$ ) of BCC and dissolved in $100 \mathrm{~cm}^{3}$ with distilled water in $250 \mathrm{ml}$ volumetric flask and left over night for complete dissolution to give $0.5-5 \%$ w/vaqueous solution of BCC, followed by adding the monomer acrylamide (AAm) of varied concentrations $1-30 \times 10^{-2}$ $\mathrm{mol} / \mathrm{Lto}$ the flask and placed in a thermostatically controlled water bath with desired temperature $\left(30-80^{\circ} \mathrm{c}\right)$. The mixture was stirred for $1 \mathrm{hr}$. The ceric-ion induce solution polymerization method was used (Sadeghi et al., 2011). The in itiat or ceric ammonium nitrate (CAN) of varied concentrations $10-40 \times 10^{-3} \mathrm{~mol} / \mathrm{L}$ was added to the mixture and continuously stirredusing a magnetic stirrer for varying periods of time (30-180 mins). The reaction was allowed retention time of $6 \mathrm{hrs}$ to form the grafted copolymer (BCC-g-PAAm). The grafted copolymer obtained was precipitated in excess acetone which was filtered and washed with a mixture of distilled water and methanol in the ratio of $(6: 4) \mathrm{ml}$ by volume; to remove the homopolymer formed. This process is repeated until no precipitation of homopolymer was observed, then the copolymer precipitate was dried to constant weight in an electrically controlled oven at $40^{\circ} \mathrm{C}$ for $24 \mathrm{hrs}$, then weighed using metler balance. The percent graft yield $(\% \mathrm{G})$ and percent grafting efficiency (\%GE) were calculated using the following relation.

$\% \mathrm{G}=(\mathrm{W} 2-\mathrm{W} 1) / \mathrm{W} 1 \times 100$

$\% \mathrm{GE}=(\mathrm{W} 2-\mathrm{W} 1) / \mathrm{W} 3 \times 100$

Where $\mathrm{W} 1, \mathrm{~W} 2$ and $\mathrm{W} 3$ represent the weight of the raw BCC, grafted BCC and monomer respectively (Sadeghi et al., 2011)

\section{Grafting mechanism}

\section{Results And Discussion}

The graft copolymer was synthesized by ceric-ion-induced polymerization method. The mechanism of copolymerization of AAm onto BCC is shown in Scheme 1 below. At the first step, a complex between the $\mathrm{Ce} 4+$ ion with the oxygen atom at the $\mathrm{C}-3$ position and the hydroxyl group at the $\mathrm{C}-2$ position were formed. This ceric-BCC complex is then dissociated to produce BCC macroradicals. The acrylamide molecules, which are in vicinity of the macroradical sites, become acceptor of $\mathrm{BCC}$ radicals resulting in chain initiation and thereafter themselves become free radical donor to the neighboring molecules leading to propagation. These grafted chains are terminated by coupling to give the graft copolymer BCC-g-PAAm (Sadeghi et al., 2011).

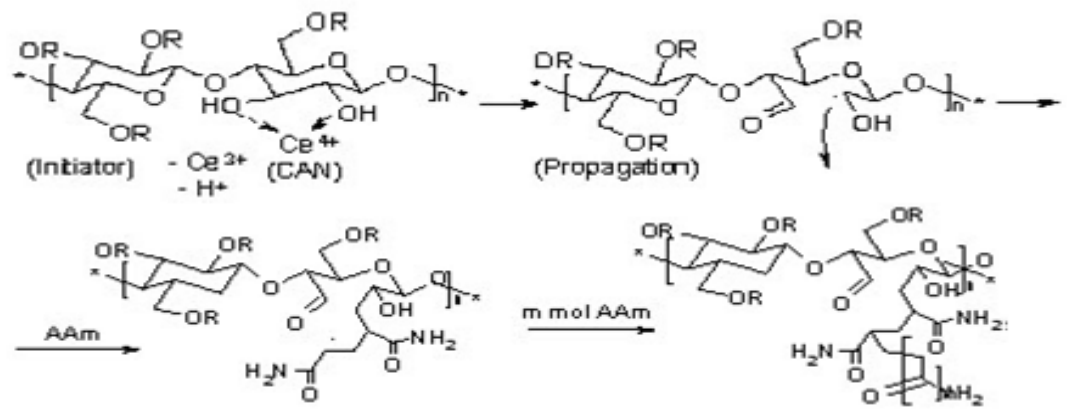


BCC-g-PAAm

Scheme 1: General mechanism for CAN-initiated graft copolymerization of acrylamide (AAm) onto BCC.

\section{FTIR Spectroscopy Analysis}

Fourier transform infrared (FTIR) spectroscopy absorption spectraof raw and grafted BCC were recorded on a JASCO FTIR-5300 spectrophotometer following the KBr disc technique in the range 4000-600 $\mathrm{cm}-1$ at room temperature.

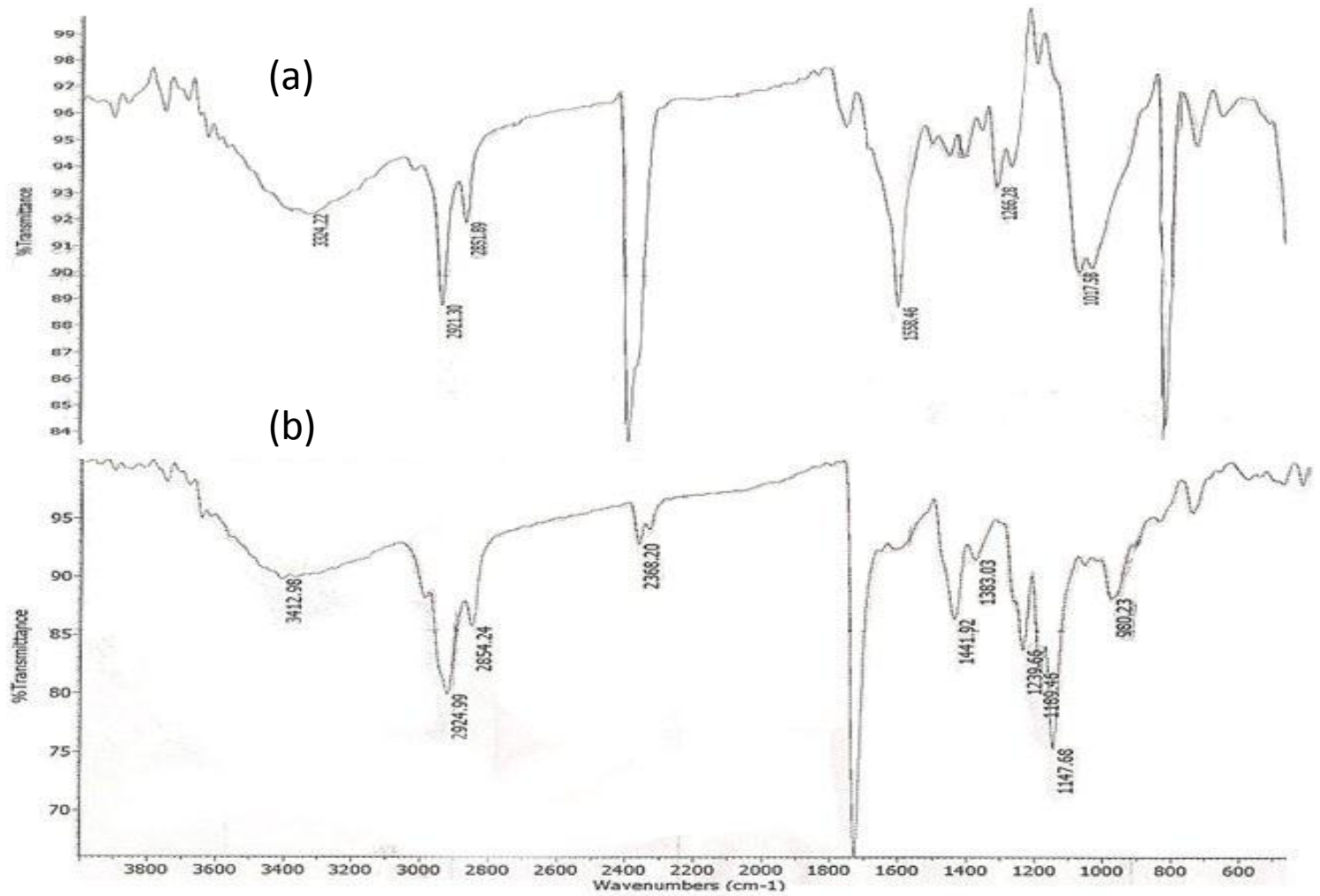

Fig. 1 FTIR spectra of raw BCC (a) and grafted BCC (b)

Fig. 1 shows FTIR spectra of raw BCC (a) and grafted BCC (b). The FTIR spectra of the raw BCC (a) show the appearance of a very broad peak at around $3440 \mathrm{~cm}^{-1}$ region. This corresponds to O-H stretching vibrations of the hydroxyl groups (Sadeghi et al., 2011). Comparing the spectra of raw BCC (a) and grafted BCC (b), it can be seen that the broad peak observed in fig. 1(a) is shifted to lower wavelengths $2362.67 \mathrm{~cm}^{-1}$ this may be as a result of the replacement of $\mathrm{O}-\mathrm{H}$ by $\mathrm{N}-\mathrm{H}$ group (Nada et al., 2007). It is expected that grafting of acrylamide onto BCC should take place at the site of the $\mathrm{O}-\mathrm{H}$ group, thus the $\mathrm{OH}$ peak intensity is consequently expected to decrease. The characteristic peak observed around $1655 \mathrm{~cm}^{-3}$ corresponds to $\mathrm{C}=\mathrm{O}$ group of the acrylamide moiety, while the bands observed around 1059,1089 and $1144 \mathrm{~cm}^{-1}$ could be assigned to C-N stretching vibrations (Sadeghi et al., 2012; Mohammad et al., 2012). These observations further support the grafting of PAAm onto the BCC backbone.

\section{Optimization of the Reaction Conditions}

In the present investigation, the effect of concentration of BCC, AAm and CAN, along with reaction time and temperature was studied, the grafting parameters were determined by weighing to optimize the reaction conditions as follows;

\section{Effect of BCC concentration}

The effect of BCC concentration on graftcopolymerization was depicted in Fig. 2 below; 


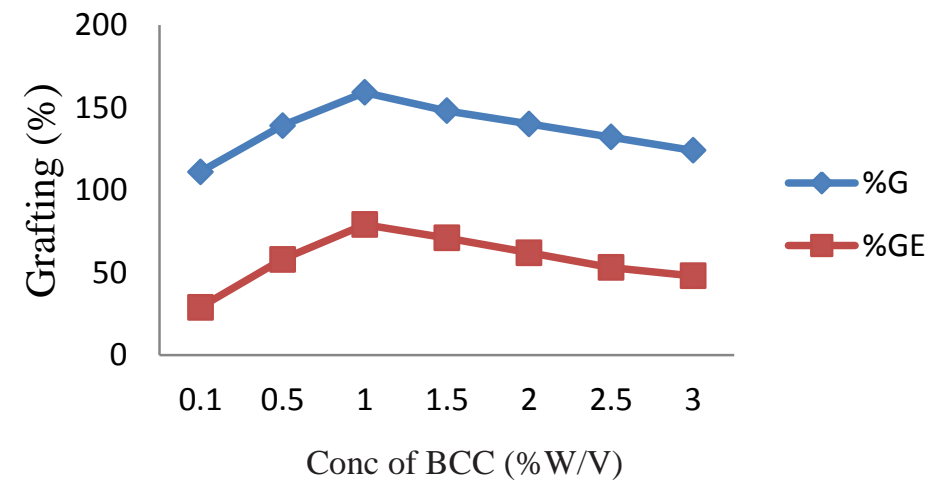

Fig.2 Effect of percentage weight by volume of $\mathrm{BCC}$ on the graft copolymerization.

(Reaction conditions; Monomer $(\mathrm{AAm})=0.15 \mathrm{~mol} / \mathrm{L}$, Initiator $(\mathrm{CAN})=0.030 \mathrm{~mol} / \mathrm{L}, \quad$ Temperature $=50^{\circ} \mathrm{C}$, Time $=120 \mathrm{mins}$ ).

With increasing the $\mathrm{BCC}$ amount, more reactive grafting sites are formed which is favorable for grafting. Thiscan account for initial increment in graftingparameters up to $1.0 \% \mathrm{~W} / \mathrm{V}$ of $\mathrm{BCC}$ value with $\% \mathrm{G}$ and $\% \mathrm{GE}$ of 159.7 and $79.4 \%$ respectively. Beyond this amount, the grafting values were decreased.This may be ascribed to the increase in viscosity ofreaction mixture and the termination reaction between macroradicalmacroradical and macroradical-primary radicals as well. This observation is in close agreement with the results obtained by other investigators (Pourjavadi et al., 2002; Mohammad et al., 2010; Sadeghi et al., 2011).

\section{Effect of Initiator Concentration}

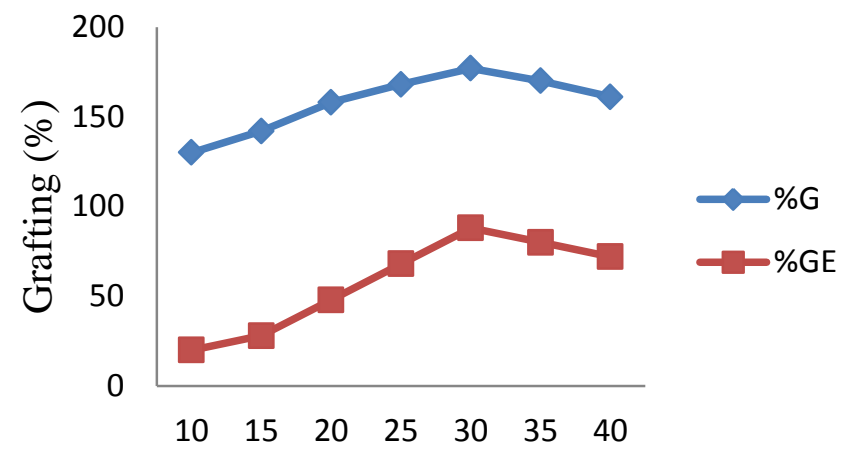

Conc of CAN $\left(\times 10^{-2} \mathrm{~mol} / \mathrm{L}\right)$

Fig.3 Effect of Initiator concentration on the graft coplymerization.

(Reaction conditions; Monomer $(\mathrm{AAm})=0.15 \mathrm{~mol} / \mathrm{L}, \quad$ Substrate $\quad(\mathrm{BCC})=1 \% \mathrm{w} / \mathrm{v}, \quad$ Temperature $=50^{\circ} \mathrm{C}$, Time $=120 \mathrm{~min}$ ).

Fig. 3 depicts the effect of the initiator concentration (CAN) on grafting of AAm onto BCC. By keeping constant all the variables, the amount of CAN used was varied. It was observed that with increasing the initiator concentration the percentage grafting yield as well as the grafting efficiency increases in the initial stages up to 177.6 and $88.3 \%$, with further increase of initiator the graft percentage as well as the grafting efficiency decreases drastically.These increasing trends of the grafting parameters indicated that ceric ions exclusively participate in the formation of free radical active sites on the BCC backbone up to this concentration of ceric ions, and beyond it, no more active sites are formed on the BCC backbone. This may be due to the fact that with high concentration of the initiator more and more homopolymers are formed thereby decreasing both $\% \mathrm{G}$ and $\% \mathrm{GE}$ of the graft copolymerization. This is obvious since ceric ion is a very good oxidizing agent with very high oxidation potential and it interacts with AAm forming the homopolymer rather than the graft copolymer at higher concentrations. This observation is in close agreement with the results obtained by other investigators (Ibrahim et al., 2002; Nada et al., 2007; Sadeghi et al., 2011).

\section{Effect of Monomer Concentration}

Fig. 3 below;

The effect of monomer concentration on graft copolymerization onto polymeric backbone is shown in 


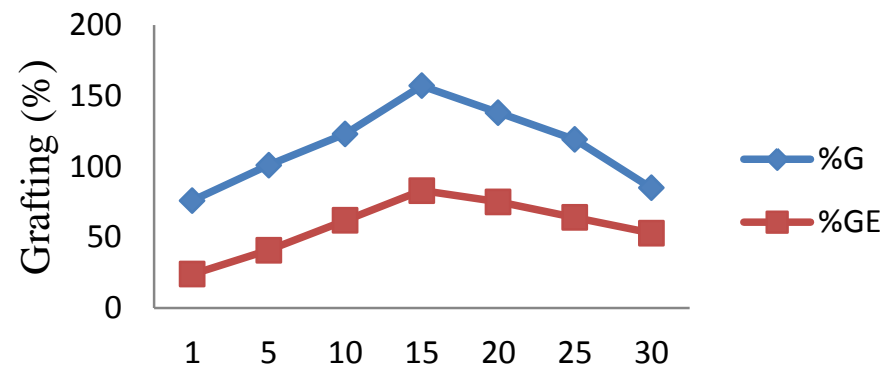

Conc of AAm $\left(\times 10^{-2} \mathrm{~mol} / \mathrm{L}\right)$

Fig.3 Effect of monomer concentration on the graft copolymerization.

(Reaction conditions; Initiator $(\mathrm{CAN})=0.030 \mathrm{~mol} / \mathrm{L}, \quad$ Substrate $\quad(\mathrm{BCC})=1 \% \mathrm{w} / \mathrm{v}$, Temperature $=50^{\circ} \mathrm{C}$, Time $=120 \mathrm{~min})$.

It can be seen from the results of Fig. 3 that as the monomer concentration increases, the $\% \mathrm{G}$ and $\% \mathrm{GE}$ increased at the initial stages up to 157.3 and $83.6 \%$ respectively. With further increase of monomer concentration it decreased. This is mainly due to the formation of homopolymer of AAm at the higher concentration as well as due to restricted movement of free radicals onto polymer backbone because of increased viscosity. These homopolymers successfully hinders the rate of penetration of monomer molecules to BCC macroradical, resulting in the low percentage of grafting. Further as the monomer concentration increases, the rate of homopolymerization increases there by decreasing the formation of graft copolymer (Okiemen et al., 2003; Nada et al., 2007; Singha et al., 2011; Sadeghi et al., 2012). The increase in the chain transfer to monomer molecules may be another possible reason for decreasing the graft polymerization. These findings are in agreement to those reported in literature (Zohuriaan et al., 2005; Zhang et al., 2007; Sadeghi et al., 2011).

\section{Effect of Reaction Temperature}

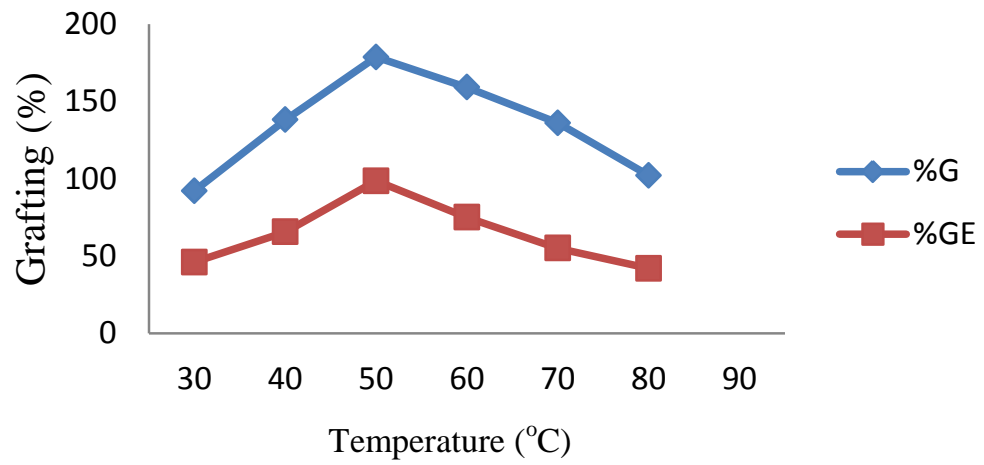

Fig.4 Effect of reaction temperature on the graft copolymerization.

(Reaction conditions; Initiator $(\mathrm{CAN})=0.030 \mathrm{~mol} / \mathrm{L}$, Substrate $(\mathrm{BCC})=1 \% \mathrm{w} / \mathrm{v}$, Monomer $(\mathrm{AAm})=0.15 \mathrm{~mol} / \mathrm{L}$, Time $=120 \mathrm{mins}$ ).

The effect of reaction temperature on the graft copolymerization was carried out at different temperatures between $30^{\circ} \mathrm{C}$ and $80^{\circ} \mathrm{C}$ and keeping the other variables constant. As shown in Fig.4, it is found that $\% \mathrm{G}$ and $\% \mathrm{GE}$ increase initially up to $50^{\circ} \mathrm{C}$ and then decrease to some extent with further increase in temperature. This is attributed to the fact that increasing the temperature favours the activation of macroradicals as well as accelerates the diffusion and mobility of the monomers from the aqueous phase to thecellulose phase. However, a further increase in temperature decreases $\% \mathrm{G}$ and $\% \mathrm{GE}$ parameters, which can be ascribed both to the acceleration of termination reaction and to the increased chance of chain transfer reaction, accounting for the increase in the amount of homopolymers. This observation indicates that the optimal reaction temperature is $50^{\circ} \mathrm{C}$. Similar behavior was observed by (Hsu et al., 2002; Kumar et al., 2011; Sadeghi et al., 2011; Sadeghi et al., 2012) 


\section{Effect of Reaction Time}

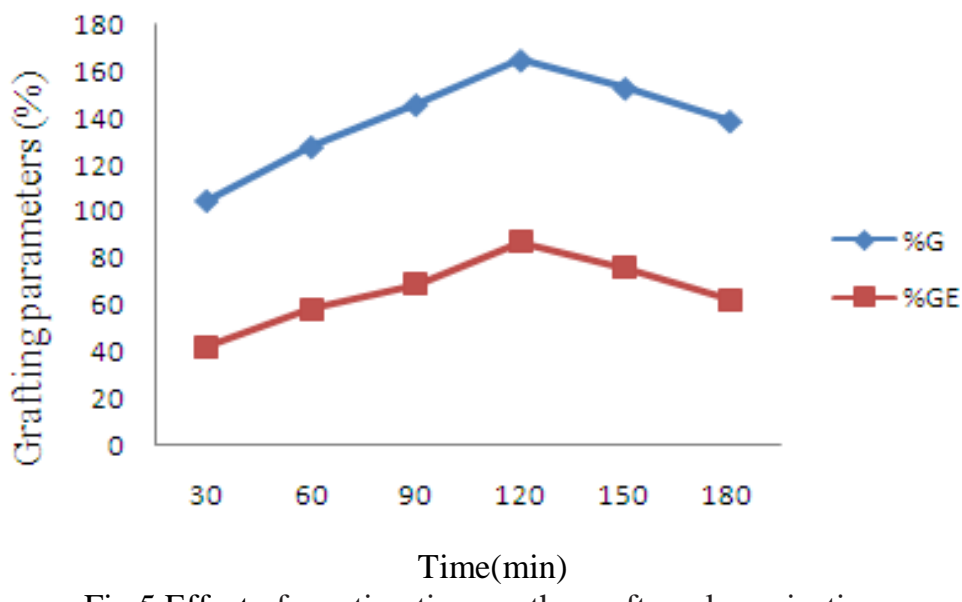

Fig.5 Effect of reaction time on the graft coplymerization.

(Reaction conditions; Initiator $(\mathrm{CAN})=0.030 \mathrm{~mol} / \mathrm{L}$, Substrate $(\mathrm{BCC})=1 \% \mathrm{w} / \mathrm{v}$, Monomer $(\mathrm{AAm})=0.15 \mathrm{~mol} / \mathrm{L}$, Temperature $\left.\left({ }^{\circ} \mathrm{C}\right)=50^{\circ} \mathrm{C}\right)$.

The effect of reaction time on $\% \mathrm{G}$ and $\% \mathrm{GE}$ is shown in Fig. 5. It can be seen that the $\% \mathrm{G}$ and $\% \mathrm{GE}$ increase rapidly with increase in time up to 120 minutes after which it decreased. Reaction time allows ceric solution to diffuse into BCC backbone prior to grafting reaction thereby allowing initiation of free radicals on cellulose sample by oxidation with CeIV ions. Initial increase in $\% \mathrm{G}$ and $\% \mathrm{GE}$ can be attributed to this factor. The decrease of the $\% \mathrm{G}$ and $\% \mathrm{GE}$ on prolonging this reaction time beyond 120 minutes could be attributed to the decay of free radical activity of CeIV oxidized cellulose resulting from the free radical termination by charge transfer. Similar trend has been observed by (Nada et al., 2007; Singha et al., 2011; Soleimani et al., 2012). Also, since there is a large excess of acrylamide monomer even after the longer reaction times, the decrease after 120 minutes is presumably due to initiator exhaustion. These observations are in accordance to those observed by (Jideonwa et al., 2006; Sadeghi et al., 2011; Singha et al., 2011).

\section{Conclusion}

Graft copolymerization was employed as an important technique to obtain a chemically modified natural polysaccharide, BCC. The grafting of AAm onto BCC was carried out using CAN as an efficient initiator. The characteristic absorbing peaks in the FTIR spectra have proven that BCC participates in graft copolymerization with AAm. The main factors affecting the grafting parameters, including concentration of the initiator, monomer, $\mathrm{BCC}$, reaction time and reaction temperature was studied. The optimum reaction conditions were found to be CAN $3.0 \times 10^{-3} \mathrm{~mol} / \mathrm{L}$, PAAm $15 \times 10^{-2} \mathrm{~mol} / \mathrm{L}, \mathrm{BCC} 1 \% \mathrm{w} / \mathrm{v}$, reaction temperature $50^{\circ} \mathrm{C}$ and reaction time $120 \mathrm{~min}$. Under the optimized conditions, the highest percentage grafting parameters were found to be $\% \mathrm{G} 178.5$ and \%GE 88.3 respectively. This result present the optimum grafting conditions required for the graft copolymerization of AAm onto BCC and hence economic yield of BCC-g-PAAm for use in determining the swelling behavior and the sorption capacity of heavy metals in the next experimental research.

\section{References}

[1]. Feng H, Li J, Wang L, (2010) Preparation of biodegradable flax shive cellulose-based superabsorbent polymer under microwave irradiation, BioResources, 5, 1484-1495.

[2]. Ge HC, Pang W, Luo DK, (2006) Graft copolymerization of chitosan with acrylic acid under microwave irradiation and its water absorbency, CarbohydrPolym, 66, 372-378.

[3]. Hsu SC, Don TM and Chiu WY (2002) Free radical degradation of chitosan with potassium persulfate. Polym. Degrad. Stab. pp: 75-73.

[4]. Ibrahim MM, Flefel EM and El-Zawawy WK (2002) Cellulose membranes grafted with vinyl monomers in homogeneous system. J. Appl. Polym. Sci. 84, 2629-2638.

[5]. Jideonwo, A, and Adimula, H.A. (2006) The Graft Copolymerization of Acrylamide onto Cellulose using Enhanced $\mathrm{Fe}^{2+} / \mathrm{H}_{2} \mathrm{O}_{2}$ redox initiator system. J. Appl. Sci. Mgt. Vol.10 (3) $151-155$.

[6]. Kaur I., Kumar R., Sharma N. (2010) Acomparative study on the graft copolymerization of acrylic acid onto rayon by a ceric ion redox system and a $\gamma$-radiation method, Carbohydr Res, 345, 2164-2173.

[7]. Khullar R., Varshney V.K., Naithani S., Soni P.L. (2008) Grafting of Acrylonitrile onto Cellulosic Material derived from Bamboo (Dendrocalamusstrictus); XPRESS Polym. Lett. Vol.2, No.1 $12-18$.

[8]. Kumar M. P., Nayak P.L. (2011) Graft Copolymerization of Acrylamide onto Chitosan for Antibacterial Activity. Int. J. Plant, Animal and Envn. Sci. Vol.1 Issue 2 Pp. $210-219$.

[9]. Mohammad S and Hossein H (2010) Studies on graft copolymerization of 2-hydroxyethylmethacrylate onto kappa-carrageenan initiated by ceric ammonium nitrate. J. Chilean Chem. Socie. 55,No 4, 348-356. 
[10]. Mohammad S., Mohammadinasab, Fatemeh S. (2012) APS-initiated graft copolymerization of N-Vinyl pyrollidone onto gelatin: preparation, characterization and optimization of grafting parameters. Sci. Res. Essays Vol.7(4) pp 511-521.

[11]. Mohammad Sadeghi and NahidGhasemi (2012) Preparation and swelling behavior of carrageenan-graftpolymethacrylamide superabsorbent hydrogel as a releasing drug system. Indian J.Sci.Technol. 5 (2) 1215-1223.

[12]. MostafaKh. M. (2005) Grafting of Methacrylamide onto Cotton Yarn Part 1: Tensile Strength; J. Appl. Sci. 5(2) 341 346.

[13]. Nada A.M.A, Mohammed Y.A, Hesham M.F (2007). Synthesis and Characterization of Grafting Cellulose for use in Water and Metal Ion Sorption Bio Res. 3 (1) $46-59$.

[14]. Okieimen, F. E., (2003) Preparation, characterization and properties of cellulose-polyacrylamide graft copolymers. J. Appl. Polym. Sci., 89: 913-923.

[15]. Onishi Y; Butler G. B; Hogen-Esch T. E (2004) 1,2- propanediol-cellulose- acrylamide Graft Copolymers. J. Appl. Polym. Sci. 92, $3022-3029$

[16]. Osemeahon, S.A. Barminas T.J., Aliyu, B.A. Nkafamiya, I.I (2008) Development of Sodium alginate and konkoli gum - graftedpolyacrylamide blend membrane: Optimization of grafting conditions. Afr. J. BiotechnolVol.7(9) 1309- 1313.

[17]. Ouajai S; Hodzic A; Shanks R. A. (2004) Morphological and Grafting Modifications of Natural Cellulosic fibres. J. Appl. Polym. Sci. 94, 2456-2465

[18]. Pourjavadi A and Zohuriaan-Mehr MJ (2002) Modification of carbohydrate polymers via grafting in air. 1. Ceric-Induced synthesis of starch-g-polyacrylonitrile in presence and absence of oxygen. Starch/Starke. 54,140-147.

[19]. Raju G, Ratnam CT, Ibrahim NA, AbRahman MZ, Yunus WZW (2007) Graft copolymerization of methyl acrylate onto oil palm empty fruit bunch (OPEFB) fibre, PolymPlastTechnol Eng, 46, 949-955.

[20]. Sadeghi M., Nalid N. G., Soleimani F. (2012) Graft Copolymerization Methacirylamide Monomer onto Carboxymethyl Cellulose in Homogenous Solution and Optimization of Effective Parameters; World Appl. Sci. J. 16 (1) 119 - 125.

[21]. Sadeghi M., Soleimani F. (2011) Optimized Graft Copolymerization of Gelating-Poly(Acrylamide-co-2-Acrylamido-2- methyl propan sulfonic acid, Oriental J. Chem.27(2): 529-536.

[22]. Sadeghi M., Soleimani F., Yarahmadi M. (2011) Chemical Modification of Carboxymethyl Cellulose Via Graft Copolymerization and Determination of the Grafting Parameters. Orient. J. Chem. Vol.27 No.(3) $967-972$.

[23]. Sadeghi, M; Synthesis of starch-gpoly( acrylic acid-co-2-hydroxy ethyl methacrylate) as potential pH-sensitive hydrogel-based drug delivery system, Turk.J. Chem. accepted (2011).

[24]. Sadeghi,M; Hosseinzadeh, H; (2010) Studies on graft copolymerization of 2-hydroxyethylmethacrylate onto kappacarrageenan initiated by ceric ammonium nitrate, J.Chil.Soc.,55,N0 4. 123-130.

[25]. Sadeghi,M; Synthesis and Characterization of Superabsorbent Hydrogel Based on Chitosan-g-Poly(Acrylic acid-co- Acrylonitrile), Afri. J.Biotechnol.accepted (2011).

[26]. Singha A.S. Rana A.K. (2011) Kinetics of Graft Copolymerization of Acrylic Acid onto Cannabis IndicaFibre Iranian Polym. J. 20(11), $913-929$.

[27]. Soleimani F., Sadeghi M., Shahsavan H. (2012) Graft Copolymerization of Gelatin-g-poly (Acrylic Acid-Acrylamide) and Calculation of Grafting Parameters; Indian J. Sci. Technol Vol. $5 \quad$ No.2 $2041-2046$.

[28]. Taghizadeh MT, Mehrdad A, (2006) Kinetic study of graft copolymerization of acrylic acid and ethyl methacrylate onto starch by ceric ammonium nitrate, Iran J ChemEng, 25, 1-10.

[29]. Zhang J, Chen H, Wang A, (2007) Study on superabsorbent composite. XV. Effects of ion-exchanged attapulgite on water absorbency of superabsorbent composites, Polym Compos, 28, 208-213.

[30]. Zohuriaan MJ, Pourjavadi A and Sadeghi M (2005) Modified CMC. 1. Optimized synthesis of Carboxymethylcellulose-gPolyacrylonitrile. Iranian Polym. J. 14(2), 131-138. 